\title{
The effect of L-arginine on serum lipids and nitrite levels, and the number of apoptotic cells, iNOS and eNOS expressions of aorta after the formation of fatty streaks in rabbit
}

\author{
Mehdi Nematbakhsh, Shaghayegh Haghjooyjavanmard, Farzaneh Mahmoodi, Ali Reza Monajemi \\ Applied Physiology Research Center and Department of Physiology, Isfahan University of Medical Sciences, \\ Isfahan, Iran
}

Received $6^{\text {th }}$ May 2008.

Revised $6^{\text {th }}$ November 2008.

Published online $1^{\text {st }}$ December 2008.

\begin{abstract}
Summary
The L-arginine is the substrate of nitric oxide production which is involved in the regulation of apoptosis and inflammatory processes. The effect of L-arginine after fatty streaks formation has not been fully understood in hypercholesterolemic model; therefore the main objective of this study was to investigate the effect of L-arginine after fatty streaks were developed in rabbit's aorta. Eighteen male rabbits were fed $1 \%$ cholesterol diet for four weeks. One third of the animals were sacrificed randomly to verify fatty streaks formation in the aorta (phase I). Then the high cholesterol diet was replaced with normal diet, and the remaining animals $(n=12)$ were divided into two groups (phase II); group $1(n=6)$ : normal diet and group $2(n=6)$ : normal diet plus L-arginine (3\% in drinking water). The experiment was continued for more four weeks. The serum levels of lipids and lipoproteins were increased significantly in phase I $(p<0.05)$, and the fatty streaks score $(1 \pm 0.44)$ indicates formation of lesions in aorta. In Phase II, no significant differences were observed between the groups for lipids and nitrite concentrations, inducible and endothelial nitric oxide synthase expressions, number of apoptotic cells, and fatty streaks development. These findings show that 3\% L-arginine for four weeks has no beneficial effect in the developed fatty streaks model.
\end{abstract}

Keywords: L-arginine - Nitric oxide - iNOS - eNOs - apoptosis - hypercholesterolemia

\section{INTRODUCTION}

Mehdi Nematbakhsh, Applied Physiology Research Center and Department of Physiology, Isfahan University of Medical Sciences, Hezar jerib Avenue, Isfahan, Iran

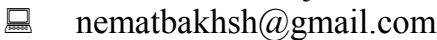

- $+98-311-7922295$
L-arginine as a nitric oxide (NO) donor with no serious adverse effects, can play an important role in improving endothelial dysfunction (ED), the suppression of inflammatory processes, the inhibition of apoptosis, the enhancement of the endothelial NO synthase (eNOS) or inducible NOS (iNOS) expressions (Preli et al. 2002, Fleming and Busse 2003, Lowenstein and Padalko 2004, Wang et al. 2005, Braam and Verhaar 2007, Kukreja and Xi 2007, Siasos et al. 2007). Its impact in atherogenesis and its ability to prevent the 
consequences of atherosclerosis risk factors on the endothelium have been studied extensively (Preli et al. 2002, Clarkson 1996, Kukreja and Xi 2007). NO is a product of L-arginine and it has also been demonstrated to be involved in the regulation of apoptosis (Nicotera et al. 1995, Li and Wogan 2005). In some cell types NO can promote apoptosis, whereas in others it inhibits apoptosis (Brüne 2003).

The eNOS protein is responsible for the classic endothelium - derived relaxing factor production, and it was originally found in endothelial cells (ECs). The exact functional significance of eNOS in the non endothelial cell type is not completely clear (Wang et al. 2005, Braam and Verhaar 2007, Kukreja and Xi 2007). The iNOS produces very large amounts of NO until L-arginine exist, and NO produced by iNOS in high concentrations can kill target cells such as bacterial and tumor cells (Taylor and Geller 2000).

Current guidelines for the prevention of atherosclerotic diseases focus on treatment of established cardiovascular risk factors to attenuate subsequent EC dysfunction and damage (Mensah et al. 2007). Some other animal studies used L-arginine in the prevention process (Cooke 1992, Böger 1995), but a question remains to be answered: can L-arginine recover ED after fatty streak (FS) lesions are formed? This present study was designed to find the effect of L-arginine on NO production, apoptosis inhibition, and eNOS and iNOS expressions in a model of rabbit after FS lesions were formed.

\section{METHODS AND MATERIALS}

\section{Animals and Experimental design}

This study was reviewed and approved by the Ethics Committee of Isfahan University of Medical Sciences. Eighteen male white Dutch-Polish rabbits $(1.95 \pm 0.25 \mathrm{~kg})$ were obtained and kept in an animal house (temperature $25^{\circ} \mathrm{C}$, size of each cage $60 \mathrm{~cm}$ x $50 \mathrm{~cm}$ x $50 \mathrm{~cm}$ ). After 1-week acclimation period and overnight fasting, blood samples were taken as pre experiment sampling.

\section{FS development}

In order to obtain FS in animals' aorta, all animals were fed rabbit chow supplemented with $1 \%$ cholesterol for four weeks. At this time blood samples were obtained again and one third of the animals were sacrificed randomly to verify FS formation in the aorta. After verification, the high cholesterol diet was omitted and normal rabbit chow re-instated. The normal rabbit chow components were starch $(560 \mathrm{~g} / \mathrm{kg})$, fibre $(280$ $\mathrm{g} / \mathrm{kg})$, grass meal $(50 \mathrm{~g} / \mathrm{kg})$, fat mixture $(40 \mathrm{~g} / \mathrm{kg})$, mineral mixture $(39.5 \mathrm{~g} / \mathrm{kg})$, calcium carbonate and bisphosphate $(25 \mathrm{~g} / \mathrm{kg})$ and a vitamin mixture $(5.5$ $\mathrm{g} / \mathrm{kg}$ ). The experimental protocol is shown in Fig. 1.

\section{L-arginine treatment}

The twelve remaining animals were divided into two groups. Group $1(n=6)$ were fed only rabbit chow, and group 2 received rabbit chow plus oral $\mathrm{L}$-arginine $[3 \%$ in drinking water] for four more weeks. Blood samples were obtained, the animals were sacrificed, and then the aortas were harvested for pathological investigation. The serum level of cholesterol, triglyceride, HDL and LDL, and nitrite (the last metabolite of NO) were measured. The FS formation, the number of apoptotic cells, iNOS and eNOS expressions were also determined.

\section{Serum lipid measurements}

Total cholesterol, HDL, and triglyceride levels were measured by standard enzymatic kit (Pars Azmoon Co., Iran)

\section{Serum nitrite measurement}

The serum level of nitrite (stable NO metabolite) was measured using a colorimetric assay kit (R\&D Systems, Minneapolis, USA) that involves the Griess reaction. Briefly, a sulphanilamide solution was added to all experimental samples, and after incubation, N-1-naphtylethylenediamine dihydrochloride solution was added. Then, absorbance was measured by a microreader in $540 \mathrm{~nm}$ wavelength. The nitrite concentration in the samples was determined by comparison to the nitrite standard reference curve. The detection limit was $0.25 \mu \mathrm{M}$ nitrite.

\section{FS determination}

The entire aorta, from the aortic arch to the external iliac arteries, was dissected out and cleaned of excess adventitial tissue. The aortas were fixed in buffered $10 \%$ formalin for $24 \mathrm{hrs}$, and then embedded in paraffin. The paraffin-embedded specimens were sectioned at $5 \mu \mathrm{m}(20$ sections in succession), stained with haematoxylin and eosin, and examined by light microscopy to determine FS by two pathologists in a double-blinded manner. FS lesions were graded as zero for no FS, 1 for existence of FS in 1-4 sections, 2 for existence of FS in 5-9 sections, 3 for existence of FS in 10-14 sections and 4 for existence of FS in 15 to all 20 sections of vessels. 
In situ detection of apoptotic cells by the terminal deoxynucleotidyl Transferase biotin-dUTP Nick End Labeling (TUNEL) method.

After dewaxation of the formalin-fixed tissue sections (aorta) according to standard procedures, the slides were placed in a plastic jar containing $200 \mathrm{ml} 0.1 \mathrm{M}$ citrate buffer, $\mathrm{pH} 6.0$, and the jar placed in a microwave oven. $350 \mathrm{~W}$ microwave irradiation was applied for $5 \mathrm{~min} .80 \mathrm{ml}$ double distilled water $\left(20-25^{\circ} \mathrm{C}\right)$ was added to the jar, and then the slides transferred into phosphate buffer saline (PBS) at 20-25 ${ }^{\circ} \mathrm{C}$. The slides were immersed for $30 \mathrm{~min}$ at room temperature in a blocking solution containing $0.1 \mathrm{M}$ Tris- $\mathrm{HCl}, 3 \%$ bovine serum albumine (BSA), and 20\% normal bovine serum, $\mathrm{pH}$ 7.5. The slides were rinsed twice with PBS at room temperature. After excess fluid was drained off, $50 \mathrm{ml}$ of TUNEL reaction mixture was applied to the section and incubated for $60 \mathrm{~min}$ at $37^{\circ} \mathrm{C}$ in a humidified chamber.

The slides were washed, and anti-fluorescein conjugated with alkaline phosphatase was added, and incubated again for $30 \mathrm{~min}$ at $37{ }^{\circ} \mathrm{C}$ in a humidified chamber. Then the slides were rinsed three times in PBS at room temperature for $5 \mathrm{~min}$ and $50 \mathrm{ml}$ BCIP-NBT substrate solutions (Roche Applied Science, Indianapolis, IN, USA) was added and incubated for $15 \mathrm{~min}$ at room temperature.

After washing the slides extensively in tap water, the slides were counterstained with hematoxylin. For the enumeration of apoptotic cells, at least 500 intimal cells were counted and the number of apoptotic cells was determined per 500 cells.

\section{Immunohistochemistry protocol for eNOS and iNOS expression in aorta}

The eNOS and iNOS expression in rabbits aorta were investigated by the immunohistochemistry (IHC) method. The antibodies were from [eNOS: Assay Designs/Stressgen Bioreagents Co., USA] and (iNOS: Cayman Chemical Co., USA). Briefly, sections $4-5 \mu \mathrm{m}$ thick were dewaxed in xylene and rehydrated in graded ethanol solutions. Endogenous peroxidase activity was blocked by $3 \%$ hydrogen peroxides. The specimens (in the case of iNOS) were permeabilized in $0.1 \%$ Triton $\mathrm{X}-100$ in PBS for 10 minutes, blocked in $20 \%$ normal goat serum in $0.01 \mathrm{M}$ PBS, and subjected to antigen retrieval in citrate buffered solution at $92{ }^{\circ} \mathrm{C}$ for 15 minutes. After being washed in PBS, the slides were incubated with iNOS antibody in a dilution of $1: 500$ and eNOS antibody in a dilution of $1: 100$. After washing in PBS the tissues were incubated by use of biotin-conjugated secondary antibody for one hour (dilution 1:400 in PBS containing 1\% BSA). Then the slides were incubated in streptavidin-biotin horseradish peroxidase complex. The eNOS and iNOS immunoreactivity was visualized by exposing the specimens to diaminobenzidine tetra hydrochloride (DAB). The sections were counterstained with hematoxylin and then rinsed and mounted.

In order to quantitatively measure the strength of colour intensity in the IHC by measuring chromogen intensity, a custom made software using C language (Microsoft Visual Studio 2005 and Dot Net framework 2.0) was developed to perform the image processing.

\section{Statistical Analysis}

The data are reported as the mean $\pm \mathrm{SE}$. A statistical software package, SPSS (version 13), was used to perform statistical analysis. The data were tested for normality and homogeneity of variance. Otherwise, the paired and unpaired Student's t-test or the Wilcoxon test were used to assess the significance of any change within and between the groups. Tested at the significant level $2 \alpha=0.05$

\section{RESULTS}

Verification of FS formation (phase I)

The data for the lipids and lipoproteins concentrations in six sacrificed animals in phase I are tabulated in Table 1. The statistical t-pair analysis indicates that total cholesterol, HDL, and triglyceride levels increased significantly in phase I $(p<0.05)$. By the end of phase I, the FS score was $1 \pm 0.44$. This score verified that the FS were formed, and the model was considered as a model of hypercholesterolemia with formed FS lesion in aorta.

Lipids, lipoproteins and nitrite concentrations, iNOS and eNOS expression, number of apoptotic cells, and score of FS formation (phase II)

The data from groups 1 and 2 are tabulated in table 2. The statistical unpaired Student's t-test analysis indicated no significant differences between the groups for lipids and nitrite concentrations, iNOS and eNOS expressions, and number of apoptotic cells. A sample picture of iNOS and eNOS expressions, and number of apoptotic cells in both groups are demonstrated in Fig. 2.

The Wilcoxon test also indicated no significant difference between the groups for FS development. 
Tab. 1. The mean of raw data (mean \pm SE) of the cholesterol, HDL and triglyceride concentrations for six sacrificed animals of phase $\mathbf{I}$

\begin{tabular}{lcc}
\hline parameter & beginning phase & end of phase I \\
\hline Cholesterol $[\mathrm{mg} / \mathrm{dl}]$ & $100.4 \pm 18.1$ & $2264.1 \pm 290.6^{\mathrm{a}}$ \\
Triglyceride $[\mathrm{mg} / \mathrm{dl}]$ & $122.5 \pm 4.9$ & $218.8 \pm 14.4^{\mathrm{a}}$ \\
HDL $[\mathrm{mg} / \mathrm{dl}]$ & $17.5 \pm 5.5$ & $92.5 \pm 21.5^{\mathrm{a}}$ \\
\hline
\end{tabular}

${ }^{a}$ significant difference form before, $\mathrm{p}<0.05$

Tab. 2. The mean of raw data (mean $\pm \mathrm{SE}$ ) of the lipids, lipoproteins and nitrite concentrations, iNOS and eNOS expression, number of apoptotic cells, and score of FS formation in groups 1 and 2

\begin{tabular}{|c|c|c|c|c|c|c|}
\hline \multirow[t]{2}{*}{ parameters } & \multicolumn{2}{|c|}{ beginning phase $\mathrm{I}^{\mathrm{a}}$} & \multicolumn{2}{|c|}{$\begin{array}{l}\text { after four weeks } \\
(\text { end of phase I) }\end{array}$} & \multicolumn{2}{|c|}{$\begin{array}{l}\text { after eight weeks } \\
\text { (end of phase II) }^{\text {a }}\end{array}$} \\
\hline & group 1 & group 2 & group 1 & group 2 & group 1 & group 2 \\
\hline Cholesterol [mg/dl] & $125.2 \pm 22.1$ & $92.7 \pm 20.8$ & $2253.2 \pm 366.4$ & $2658.2 \pm 394.1$ & $1222.2 \pm 198.9$ & $1433.4 \pm 161.4$ \\
\hline Triglyceride [mg/dl] & $114.9 \pm 1.3$ & $123.4 \pm 6.5$ & $198.4 \pm 8.8$ & $277.8 \pm 40.5$ & $97.2 \pm 48.8$ & $153.8 \pm 19.2$ \\
\hline $\mathrm{HDL}[\mathrm{mg} / \mathrm{dl}]$ & $15.2 \pm 3.9$ & $17 \pm 3.2$ & $82 \pm 13.1$ & $101.2 \pm 12.8$ & $79 \pm 1.7$ & $81.5 \pm 10.1$ \\
\hline $\operatorname{Nitrite}[\mu \mathrm{mol} / 1]$ & $9.94 \pm 2.05$ & $11.10 \pm 0.40$ & $12.45 \pm 1.24$ & $13.54 \pm 0.42$ & $17.96 \pm 2.74$ & $14.58 \pm 2.06$ \\
\hline $\begin{array}{l}\text { iNOS expression } \\
\text { (intensity) }\end{array}$ & - & - & - & - & $12.2 \pm 4.18$ & $10 \pm 3.00$ \\
\hline eNOS expression (intensity & y) - & - & - & - & $17.4 \pm 5.83$ & $24.5 \pm 6.50$ \\
\hline Apoptotic cells $/ 500$ cells & - & - & - & - & $41.2 \pm 12.2$ & $61.2 \pm 28.6$ \\
\hline FS score & - & - & - & - & $1.83 \pm 0.60$ & $2 \pm 0.63$ \\
\hline
\end{tabular}

$\overline{\text { a The Wilcoxon test (for FS score) and unpaired Student's t-test (for other parameters) indicated no significant differences }}$ between the groups.

\section{DISCUSSION}

The main objective of this study was to determine the effect of L-arginine treatment on NO production, apoptosis inhibition, and eNOS and iNOS expressions after established FS lesion in an animal model. The results indicate that after four weeks of experiment (phase I), the high cholesterol diet increased the serum level of lipids and lipoproteins concentration, and it also formed FS lesions in the animal aorta. These data support and verify the model as an established model of hypercholesterolemia and formed lesions. The L-arginine treatment in phase II indicates no significant effect on serum lipids and lipoproteins and nitrite concentrations, number of apoptotic cells, eNOS and iNOS expressions, and FS formation.

It is reported that L-arginine supplementation in model of hypercholesterolemia had no effect on serum lipids and lipoproteins (Wang 1994, Böger 1997); that is in agreement with our results. An 


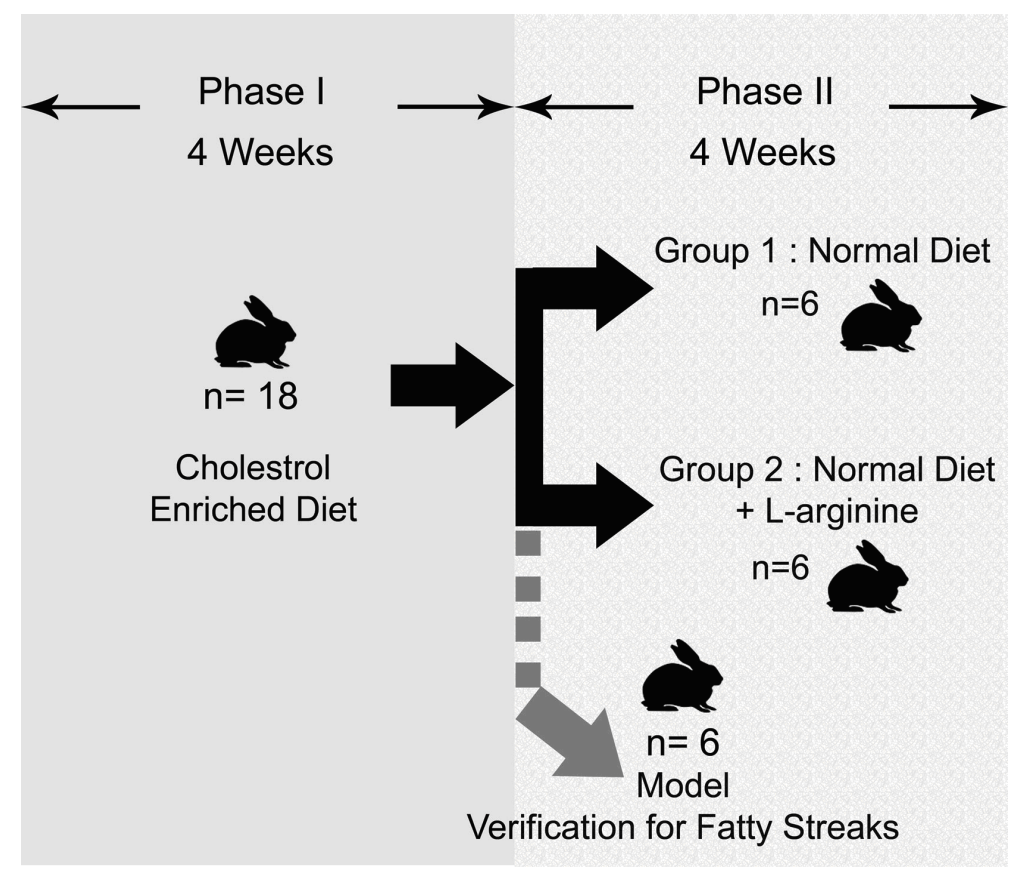

Fig.1. The experimental protocol for two phases of study. Six animals were sacrifices by the end pf phase I to verify the formation of FS. The Phase II was continued with twelve animals in two groups of normal diet (group 1) and L-arginine (group 2).

increased plasma level of nitrite has been reported in the enriched cholesterol animal model (Minor et al. 1990, Nematbakhsh et al. 2002, Moroe and Honda 2006,). It is suggested that enhanced NO synthesis might be a defense mechanism to compensate continuous inactivation of $\mathrm{NO}$ and protection towards damaging factors such as hypercholesterolemia (Cai and Harrison 2000). However, when the damage was established, the activity of eNOS decreased, but NO are produced by iNOS in macrophages and other cell types in atherosclerosis (Nachtigal et al. 2005, Hayashi et al. 2006). It seems that one of the most important underlying mechanisms of the beneficial effect of L-arginine is enhancement of eNOS protein expression. The eNOS gene transfer showed improvement in the endothelial function and inhibition or regression of atherosclerotic lesions in animal models (Hayashi et al. 2004, Mujynya-Ludunge et al. 2005). Although strong evidence suggests that eNOS plays an important role in protection of the vessel wall from atherosclerosis, iNOS may contribute to the formation of lesions by increasing oxidative stress in the vessel wall (Wilcox et al. 1997). Multiple lines of evidence also support the notion that delayed treatment with L-arginine increases apoptosis via stimulation of NO production from iNOS with subsequent increase of toxic peroxynitrite anion ONOO! formation (Björkerud and Björkerud 1996, Stefanec 2000). However, that protective effect by L-arginine could also be mediated through non-eNOS-dependent pathways, since L-arginine also has anti oxidant effects. (Jabłecka et al. 2004). So far there are many reports available about L-arginine and its positive (Wang 1994, Adams 1997, Preli et al. 2002, Suzuki et al. 2002, Siasos et al. 2007) or harmful (Tousoulis et al. 2007) effects on the vascular system, but our findings may have revealed that L-arginine has more beneficial effect when used as a preventive agent not a treatment substance, and of course more studies are needed.

\section{ACKNOWLEDGMENT}

This study was supported by Isfahan University of Medical sciences, Isfahan, Iran and Stem Cell Technology Co., Tehran, Iran. 


\section{A: eNOS expression}

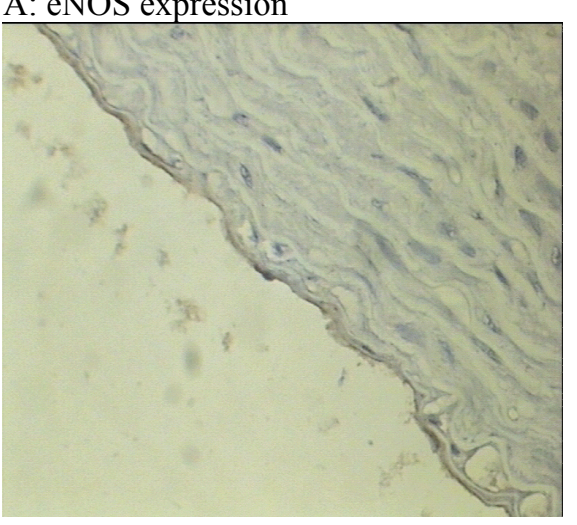

Group 1

\section{B: iNOS expression}

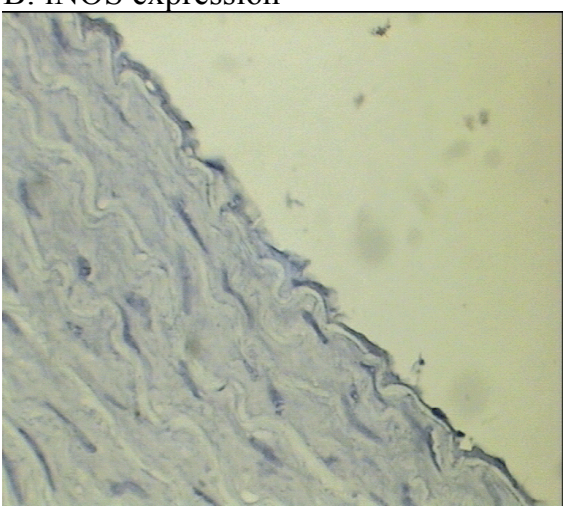

Group 1

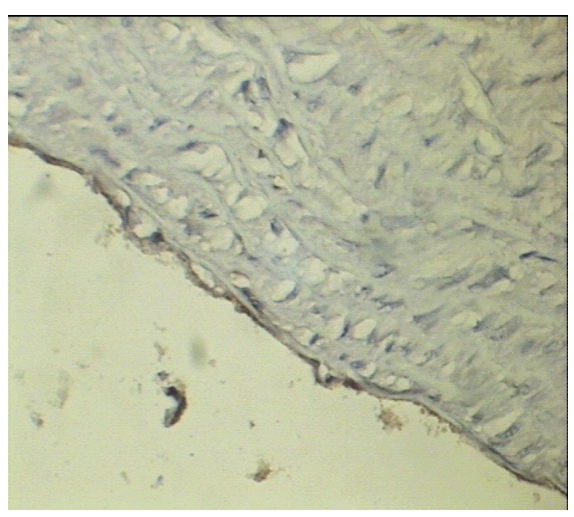

Group 2

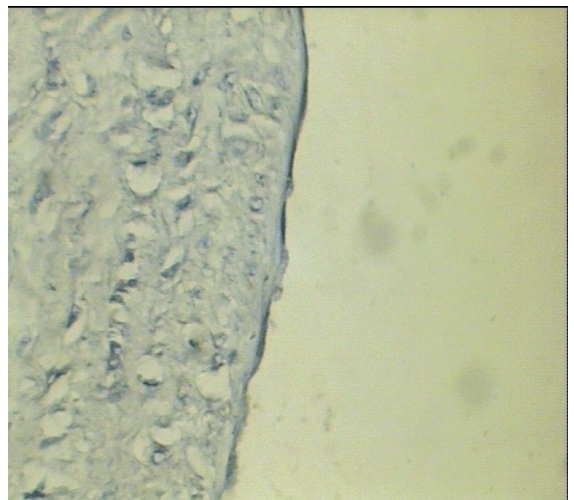

Group 2

Fig.2. The (A) eNOS and (B) iNOS expressions in two groups of normal diet (group 1) and L-arginine group (group 2) by immuohistochemistery methods. There are no significant differences between two groups` intensities.

\section{REFERENCES}

Adams MR: Oral L-arginine improves endothelium dependent dilatation and reduces monocyte adhesion to endothelial cells in young men with coronary disease. Atherosclerosis 129:261-169, 1997.

Björkerud S, Björkerud B: Apoptosis is abundant in human atherosclerotic lesions especially in inflammatory cells (macrophages and $\mathrm{T}$ cells; and may contribute to the accumulation of gruel and plaque instability. Am. J. Pathol. 149:367-380, 1996.

Böger RH: Supplementation of hypercholesterolemic rabbits with $\mathrm{L}$ arginine reduces vascular release of superoxide anions and restores NO production. Atherosclerosis 117:273-284, 1995.

Böger RH: Dietary L-arginine reduces the progression of atherosclerosis in cholesterol-fed rabbits: comparison with lovastatin. Circulation 96:282-1290, 1997.

Braam B, Verhaar MC: Understanding eNOS for pharmacological modulation of endothelial function: a translational view. Curr. Pharm. Des. 13:1727-1740, 2007.

Brüne B: Nitric oxide: NO apoptosis or turning it ON? Cell Death Differ. 10:864-869, 2003. 
Clarkson P: Oral L-arginine improves endothelium-dependent dilation in hypercholesterolemic young adults. J. Clin. Invest. 97:1989-1994, 1996.

Cai H, Harrison DG: Endothelial dysfunction in cardiovascular diseases: the role of oxidant stress. Circ. Res. 87:840-844, 2000.

Cooke JP: Antiatherogenic effects of L-arginine in the hypercholesterolemic rabbit. J. Clin. Invest. 90:1168-1172, 1992.

Fleming I, Busse R: Molecular mechanisms involved in the regulation of the endothelial nitric oxide synthase. Am. J. Physiol. Regul. Integr. Comp. Physiol. 284:R1-R12, 2003.

Hayashi T, Sumi D, Juliet PA, Matsui-Hirai H, Asai-Tanaka Y, Kano H, Fukatsu A, Tsunekawa T, Miyazaki A, Iguchi A, Ignarro LJ: Gene transfer of endothelial NO synthase but not eNOS plus inducible NOS regressed atherosclerosis in rabbits. Cardiovasc. Res. 61:339-351, 2004.

Hayashi T, Matsui-Hirai H, Fukatsu A, Sumi D, Kano-Hayashi H, Rani P, Iguchi A: Selective iNOS inhibitor ONO1714 successfully retards the development of high-cholesterol diet induced atherosclerosis by novel mechanism. Atherosclerosis 187:316-24, 2006.

Jabłecka A, Checiñski P, Krauss H, Micker M, Ast $\mathrm{J}$ : The influence of two different doses of L-arginine oral supplementation on nitric oxide (NO) concentration and total antioxidant status (TAS) in atherosclerotic patients. Med. Sci. Monit. 10:CR29-CR32, 2004.

Kukreja RC, Xi L: eNOS phosphorylation: a pivotal molecular switch in vasodilation and cardioprotection? J. Mol. Cell. Cardiol. 42:280-282, 2007.

Li CQ, Wogan GN: Nitric oxide as a modulator of apoptosis. Cancer. Lett. 226:1-15, 2005.

Lowenstein CJ, Padalko E: iNOS (NOS2) at a glance. J. Cell. Sci. 117:2865-2867, 2004.

Mensah GA, Ryan US, Hooper WC, Engelgau MM, Callow AD, Kapuku GK, Mantovani A: Vascular endothelium summary statement II: Cardiovascular disease prevention and control. Vascul. Pharmacol. 46:318-320, 2007.

Minor RL, Myers PR, Guerra R, Bates JN, Harrison DG: Diet-induced atherosclerosis increases the release of nitrogen oxides from rabbit aorta. J. Clin. Invest. 86:2109-2116, 1990.

Moroe H, Honda H: Comparison of endothelial function in the carotid artery between normal and short-term hypercholesterolemic rabbits. Comp. Biochem. Physiol. C, Comp. Pharmacol. Toxicol. 144:197-203, 2006.
Mujynya-Ludunge K, Viswambharan H, Driscoll R, Ming XF, von Segesser LK, Kappenberger L, Yang Z, Vassall G: Endothelial nitric oxide synthase gene transfer restores endothelium-dependent relaxations and attenuates lesion formation in carotid arteries in apolipoprotein E-deficient mice. Basic. Res. Cardiol. 100:102-111, 2005.

Nachtigal P, Kopecky M, Solichova D, Zdansky P, Semecky V: The changes in the endothelial expression of cell adhesion molecules and iNOS in the vessel wall after the short-term administration of simvastatin in rabbit model of atherosclerosis. J. Pharm. Pharmacol. 57:197-203, 2005.

Nematbakhsh M, Hayat-Davoodi P, Rajabi P, Samarian SH: The effect of estrogen on endothelial permeability of aorta and the level of serum nitrite concentration in cholesterol-fed ovariectomized rabbit. Iran Biomed. J. 6:77-82, 2002.

Nicotera P, Bonfoco E, Brüne B: Mechanisms for nitric oxide-induced cell death: involvement of apoptosis. Adv. Neuroimmunol. 5:411-20, 1995.

Preli RB, Klein KP, Herrington DM: Vascular effects of dietary L-arginine supplementation Atherosclerosis 162:1-15, 2002.

Siasos G, Tousoulis D, Antoniades C, Stefanadi E, Stefanadis C: L-arginine the substrate for NO synthesis: an alternative treatment for premature atherosclerosis? Int. J. Cardiol. 116:300-308, 2007.

Stefanec T: Endothelial apoptosis: could it have a role in the pathogenesis and treatment of disease? Chest 117:841-54, 2000.

Suzuki T, Hayase M, Hibi K, Hosokawa H, Yokoya K, Fitzgerald PJ, Yock PG, Cooke JP, Suzuki T, Yeung AC: Effect of local delivery of L-arginine on in-stent restenosis in humans. Am. J. Cardiol. 89:363-367, 2002.

Taylor BS, Geller DA: Molecular regulation of the human inducible nitric oxide synthase (iNOS) gene. Shock 13:413-24, 2000.

Tousoulis D, Böger RH, Antoniades C, Siasos G, Stefanadi E, Stefanadis C: Mechanisms of disease: L-arginine in coronary atherosclerosis a clinical perspective. Nat. Clin. Pract. Cardiovasc. Med. 4:274-283, 2007.

Wang BY: Dietary arginine prevents atherogenesis in the coronary artery of hypercholesterolemic rabbits. J. Am. Coll. Cardiol. 23:452-458, 1994.

Wang X, Cade R, Sun Z: Expression of human eNOS in cardiac and endothelial cells. Methods Mol. Med. 112:91-107, 2005.

Wilcox JN, Subramanian RR, Sundell CL, Tracey 
Nematbakhsh et al.: The effect of L-arginine on serum lipids

WR, Pollock JS, Harrison DG, Marsden PA: Expression of multiple isoforms of nitric oxide synthase in normal and atherosclerotic vessels.
Arterioscler. Thromb. Vasc. Biol. 17:2479 $-2488,1997$. 